\title{
Microworm Culture for Use in Freshwater Ornamental Aquaculture ${ }^{1}$
}

\author{
Shane W. Ramee, Taylor N. Lipscomb, and Matthew A. DiMaggio²
}

\section{Introduction}

Rearing larval fish is one of the most challenging aspects of aquaculture, and many bottlenecks must be overcome for successful production. During the larval phase, fish are at their most sensitive and may have very specific nutritional demands that must be met to ensure their growth and survival. Many species in commercial production require small live feed organisms during first feeding and the larval stages and cannot survive on inert diets. The freshwater ornamental fish industry relies heavily on newly hatched Artemia (brine shrimp) as a first-feed item, but prices for Artemia are volatile and labor costs associated with them are frequently high. Finally, they are often difficult to source. For over 50 years, aquarium hobbyists and the aquaculture industry have used a small nematode worm commonly called a "microworm" as an alternative to brine shrimp for larval fish that need live feed. These worms are small enough for larvae of many commonly cultured ornamental species to ingest, and production methods for microworms are simple and reliable. Microworms provide appropriate nutrition for many species and can be cultured entirely in house, involving less labor and lower costs than newly hatched Artemia. Microworms offer excellent potential to diversify a facility's live feeds and available larval diets and can potentially help lower feed costs. However, microworms are not a nutritionally complete diet for all species and should be used on a case-by-case basis.

\section{Biology}

"Microworms" is the common name for the group of microscopic white nematodes used as a feed for larval fishes. The two most common species used in aquaculture are Anguillula silusiae and Panagrellus redivivus. Their small size (less than $3 \mathrm{~mm}$ ) and active movement make them an attractive food for first feeding larval fish. Their elongated body shape (Figure 1) makes them easy prey for smallmouthed larvae to consume.

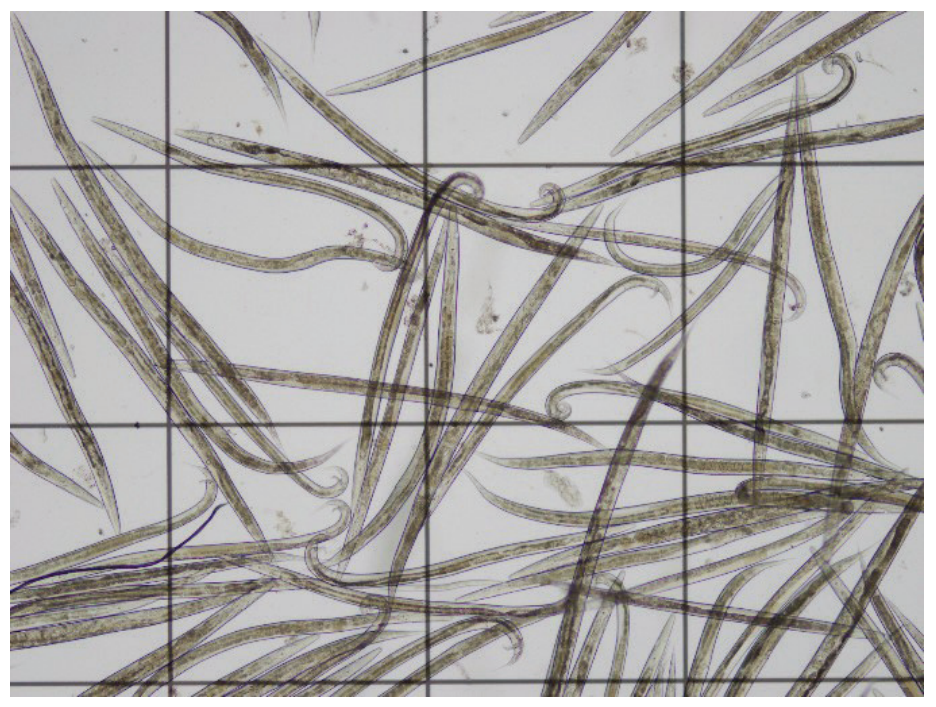

Figure 1. Microscopic image of adult microworms on a $1 \mathrm{~mm}$ grid. Under the microscope, their white, unsegmented, elongated bodies can be easily seen in constant motion.

1. This document is FA214, one of a series of the School of Forest Resources and Conservation, Program in Fisheries and Aquatic Sciences, UF/IFAS Extension. Original publication date April 2019. Visit the EDIS website at https://edis.ifas.ufl.edu for the currently supported version of this publication.

2. Shane W. Ramee, PhD student; Taylor N. Lipscomb, PhD student; and Matthew A. DiMaggio, assistant professor; Program in Fisheries and Aquatic Sciences, School of Forest Resources and Conservation, UF/IFAS Tropical Aquaculture Laboratory, Ruskin, FL 33570. 
Microworms reach sexual maturity within about 3 days and are sexually dimorphic, with the males being smaller and having a curled tail. Sex ratios are always skewed towards females, with 1.20 to 3.75 females per male, depending on the age of the culture (Hoff and Snell 1987). Females are ovoviviparous, meaning they internally incubate their progeny and give live birth to juvenile nematodes. Juvenile microworms are about 180 to $290 \mu \mathrm{m}$ long and $0.13 \mu \mathrm{m}$ wide; adults are 1500 to $2000 \mu \mathrm{m}$ in length with an average width of 50 to $70 \mu \mathrm{m}$ (Figure 1, Brüggemann 2012). Depending on a female's age and size, she can give birth to between 7 and 40 progeny every 1 to 1.5 days, ultimately producing approximately 15 broods and 300 progeny in her lifetime.

\section{Environmental Requirements}

Microworms thrive in a broad temperature range. It is possible to grow them in temperatures from $1.5^{\circ} \mathrm{C}\left(35^{\circ} \mathrm{F}\right)$ to at least $28^{\circ} \mathrm{C}\left(82^{\circ} \mathrm{F}\right)$. Growth rates and lifespans of microworm cultures are temperature dependent. At lower temperatures, cultures produce more slowly but are viable longer, while at higher temperatures, cultures produce more quickly but are productive for a shorter duration of time. It has been suggested that the ideal temperature range for microworm culture is between $21^{\circ} \mathrm{C}$ and $27^{\circ} \mathrm{C}\left(70^{\circ} \mathrm{F}-80^{\circ} \mathrm{F}\right.$, Hoff and Snell 1987). Nematodes have broad $\mathrm{pH}$ tolerances but generally do best in acidic conditions. Optimal culture growth occurs in a $\mathrm{pH}$ range of 3.4 to 4.2 , which, due to the fermentation process, naturally occurs within 3 to 4 days. Despite living in decaying and fermenting substrates, microworms cannot survive in anaerobic conditions. This is why the worms are often seen in large congregations on the surface of the substrate or on the sides of the culture container. It is therefore recommended to use a culture container with moderate air flow.

\section{Culture Techniques}

Starter cultures of microworms can be purchased through a variety of biological, aquaculture, or aquarium supply companies. Alternatively, a small amount of an existing culture can be obtained from other culturists or hatcheries. Culture systems can come in a variety of shapes and sizes but should be kept as simple as possible. A plastic shoebox or shallow bin with high surface area and moderate depth (about 6 to $10 \mathrm{~cm}$ deep) makes an ideal culture container. The culture container should have a loosely fitting lid or small holes to allow air exchange without excessive evaporation. The culture medium can be anywhere from 1 to $4 \mathrm{~cm}$ deep and should be approximately 6 to $8 \mathrm{~cm}$ from the top of the culture container. The extra freeboard above the medium is important because it allows for easy harvest of the microworms after they crawl up the sides of the container. A spatula, paint scraper, or credit card can be used to scrape the worms off the side off the container.

The standard culture medium is made of a mix of oatmeal, yeast, and water, but several other formulations have been used successfully. Some culturists prefer baby food oatmeal due to its finer consistency and more rapid colony development, but bulk bags of rolled oats may be more economical for large-scale production. Alternatively, a mixture of stale beer and oatmeal or stale bread has also been successfully used as a microworm culture medium. Studies have shown that shrimp larvae survive and grow faster after being fed nematodes grown in a 50/50 wheat- and corn-flour-based growth medium compared to an oats-based medium (Focken et al. 2006). Additionally, the development of a specially formulated purified ingredient medium resulted in higher concentrations of nematodes than a simple oatsbased medium (Ricci et al. 2003).

While these studies shed light on optimum microworm rearing conditions, for production purposes the mixture of ingredients in the culture medium does not need to be very precise. An example recipe intended to fill a plastic shoebox consists of $7 \mathrm{~g}$ ( $0.5 \mathrm{Tbsp}, 0.25 \mathrm{oz}$ ) of yeast Saccharomyces cerevisiae mixed with $500 \mathrm{~mL}$ of water and $250 \mathrm{~mL}$ of oatmeal. This recipe will have to be scaled depending on the volume of the culture container being used. The culture medium should a have thick, paste-like consistency and a yeasty aroma (Chappell 2013). It is important that the medium not be too runny; if it is watery, a film of bacteria will grow on the culture and inhibit the growth of the microworm colony. The growth medium should be 1 to $4 \mathrm{~cm}$ thick in the bottom of the culture container. Microworms only occupy the top $5 \mathrm{~mm}$ of the culture medium, but the extra depth prevents the culture from drying out and reduces the frequency of culture transfers. Keep the medium off the sides of the culture container to prevent inadvertently collecting it when harvesting microworms.

After a new culture container is inoculated with a spoonful of microworms from an old culture, it takes approximately a week for the culture to become productive. At this time, the microworms will actively crawl up the sides of the culture container in response to the high density of the culture. These microworms can easily be harvested by scraping them off the sides of the culture container and can be fed directly the fish without first cleaning them. They can also be added to a small volume of water so that they may be more easily quantified before they are distributed to fry tanks. 
The life span and growth rate of a culture is dependent on temperature. At 18 to $20^{\circ} \mathrm{C}\left(64\right.$ to $\left.68^{\circ} \mathrm{F}\right)$, P. redivivus populations peak within 10 to 11 days. Once the culture begins to deteriorate, the medium will begin to liquefy, darken, and take on a rancid odor. At that point if nothing is done, the culture will continue to deteriorate and eventually will die. To salvage a deteriorating culture, mix up new media and start new cultures, or extend the lifespan of the existing culture by adding more baby oatmeal and yeast to it. This should be done once the culture medium becomes runny, but before it begins to smell foul. Refreshing media can keep cultures productive for up to 3 months at $20^{\circ} \mathrm{C}$ or 6 weeks at $28^{\circ} \mathrm{C}$. An active $20-\mathrm{X} 30-\mathrm{cm}(\sim 8-\mathrm{X} 12$-in) culture produces approximately 5 to $8 \mathrm{~mL}$ ( $\sim 1$ to 1.5 teaspoons) of microworms per day, and costs for the supplies and the medium are less than US\$10. Inactive cultures can be stored in the refrigerator, and in some cases the freezer, for months at a time and will resume growing when they warm up.

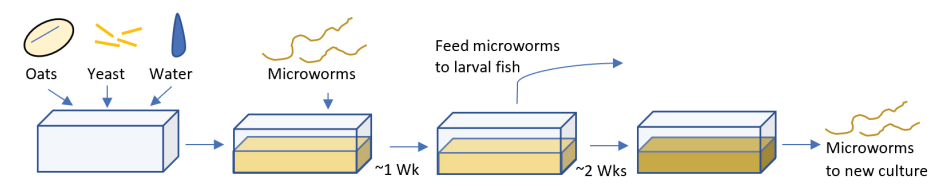

Figure 2. Schematic of a microworm culture cycle.

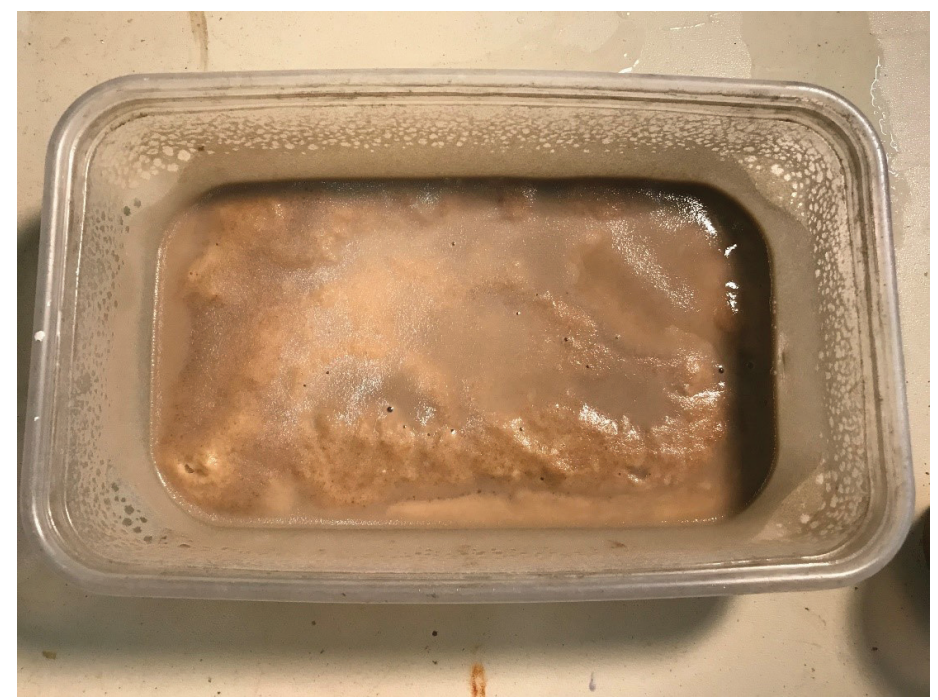

Figure 3. A top down image of an example of an active microworm culture with microworms crawling up the sides of the culture container.

\section{Nutritional Value}

The nutritional content of microworms varies depending on the specific culture conditions and the medium on which they are reared. It has been reported that microworms are $76 \%$ water and $24 \%$ dry material (Hoff and Snell 1987). The dry matter contains $40 \%$ protein and $19.5 \%$ fat. This high fat content makes them a particularly attractive food source for larval fish. Experiments have shown that microworms can be enriched by adding vitamins A, B, C, and $\mathrm{D}$ to their media, resulting in improved larval quality. Microworms enriched with fish oils have higher levels of highly unsaturated fatty acids (HUFAs). Microworms have also been enriched with the carotenoid astaxanthin, which can enhance pigmentation in some fish species. Shrimp fed either of these enriched microworms survived better than non-enriched controls (Kumlu et al. 1998). Nematodes may not be the ideal first feed for all species of fish, however. Bighead carp and Asian catfish did not perform as well when fed microworms as they did when fed Artemia (Santiago et al. 2003).

\section{Use of Microworms in Larviculture}

Once microworms are harvested from the culture container, they may be fed out directly based on volume or weight of the dry nematodes, or they may be mixed into a small volume of water to be enumerated volumetrically. This is done by homogenizing the microworms in a water mixture, removing a known volume (usually $1 \mathrm{~mL}$ or less) with a pipette, and counting the number of nematodes in that subsample under a dissecting microscope. This is a more precise way to determine the number of organisms fed to cultured larvae. Microworms generally sink in fresh water, making them ideal for species that feed benthically but perhaps not as effective for larvae that feed higher in the water column. Once harvested, microworms can stay alive in freshwater for approximately 12 hours.

Microworms, particularly $P$. redivivus, have been successfully used as a live feed organism in the larval culture of many different species of fish and crustaceans. Larvae of important carp species, including grass carp, Ctenopharyngodon idella, silver carp, Hypophthalmichthys molitrix, and bighead carp, Hypophthalmichthys nobilis have all been successfully raised with $P$. redivivus as the sole feed item (Sautter et al. 2007; Schlechtriem et al. 2004). Additionally, whitefish, Coregonus lavaretus, larvae exhibit high levels of digestion and assimilation of this microworm, indicating it is an appropriate feed organism (Schlechtriem et al. 2005). Widely aquacultured shrimp species, including Penaeus indicus and Litopenaeus vannamei, have also been successfully raised through the larval stages using $P$. redivivus (Focken et al. 2006; Kumlu et al. 1998). Many species of freshwater ornamental fish also accept $P$. redivivus, including tetras, barbs, and cyprinids among others; however, research in this area is lacking. While A. silusiae is not as well studied as $P$. redivivus, preliminary data indicate similar feeding success with this microworm species, particularly with ornamental fish (Malla and Banik 2015; Weerasooriya et al. 1999). 


\section{Conclusions}

Microworms have the potential for inclusion in the larval nutrition protocols of numerous freshwater aquaculture species. Simple and reliable production techniques also make these species an attractive choice as a live feed. Though microworms have shown to be a successful first feed item for many species of fish, it is important to recognize that nutritional requirements can differ greatly among species, and live feed organisms should be evaluated on a case-by-case basis. Producers considering using microworms should start with smaller cultures and begin by testing the effectiveness of microworms on a small group of larvae. Microworms may also be used as a co-feed with Artemia to provide a more diverse diet. Techniques delineated in this manuscript should allow producers to establish productive microworm cultures that will support commercial production of a variety of freshwater fish species.

\section{References}

Brüggemann, J. 2012. "Nematodes as live food in larviculture-a review." J World Aquacult Soc 43:739-763

Chappell, J. A. 2013. "Culture Of Microworms (Panagrellus sp.) As An Alternative to Brine Shrimp for Larval Fish Forage." Auburn University:1-3 (https://agrilifecdn.tamu. edu/fisheries/files/2013/09/Culture-O-MicrowormsPanagrellus-sp.-As-An-Alternative-to-Brine-Shrimp-forLarval-Fish-Forage.pdf).

Focken, U., C. Schlechtriem, M. Von Wuthenau, A. GarcíaOrtega, A. Puello-Cruz, and K. Becker. 2006. "Panagrellus redivivus mass produced on solid media as live food for Litopenaeus vannamei larvae." Aquacult Res 37:1429-1436

Hoff, F. H., and T. W. Snell. 1987. Plankton Culture Manual. fifth edn. Florida Aqua Farms, Inc., Dade City, Florida

Kumlu, M., D. Fletcher, and C. Fisher. 1998. "Larval pigmentation, survival and growth of Penaeus indicus fed the nematode Panagrellus redivivus enriched with astaxanthin and various lipids." Aquacult Nutr 4:193-200

Malla, S., and S. Banik. 2015. "Production and application of live food organisms for freshwater ornamental fish Larviculture." Adv in Bioresearch 6

Ricci, M., A. Fifi, A. Ragni, C. Schlechtriem, and U. Focken. 2003. "Development of a low-cost technology for mass production of the free-living nematode Panagrellus redivivus as an alternative live food for first feeding fish larvae." Appl Microbiol Biotechnol 60:556-559

Santiago, C., A. Gonzal, M. Ricci, and S. Harpaz. 2003. "Response of bighead carp Aristichthys nobilis and Asian catfish Clarias macrocephalus larvae to free-living nematode Panagrellus redivivus as alternative feed." J of App Ichth 19:239-243

Sautter, J., H. Kaiser, U. Focken, and K. Becker. 2007. "Panagrellus redivivus (Linné) as a live food organism in the early rearing of the catfish Synodontis petricola (Matthes)." Aquacult Res 38:653-659

Schlechtriem, C., U. Focken, and K. Becker. 2005. "Digestion and Assimilation of the Free-living Nematode Panagrellus redivivus Fed to First Feeding Coregonid Larvae: Evidence from Histological and Isotopic Studies." J World Aquacult Soc 36:24-31

Schlechtriem, C., M. Ricci, U. Focken, and K. Becker. 2004. "Mass produced nematodes Panagrellus redivivus as live food for rearing carp larvae: preliminary results." Aquacult Res 35:547-551

Weerasooriya, A., U. Edirisinghe, P. Silva, and C. Dematawewa. 1999. "Feeding behaviour and acceptability of different feeds by Puntius nigrofasciatus." Trop Agricult Res 11: 221-228. 